\title{
Intraoperative risks of radiation exposure for the surgeon and patient
}

\author{
Nathaniel W. Jenkins, James M. Parrish, Evan D. Sheha, Kern Singh \\ Department of Orthopaedic Surgery, Rush University Medical Center, Chicago, IL, USA \\ Contributions: (I) Conception and design: All authors; (II) Administrative support: All authors; (III) Provision of study materials or patients: All \\ authors; (IV) Collection and assembly of data: All authors; (V) Data analysis and interpretation: All authors; (VI) Manuscript writing: All authors; (VII) \\ Final approval of manuscript: All authors. \\ Correspondence to: Kern Singh, MD. Professor, Department of Orthopaedic Surgery, Rush University Medical Center, 1611 W. Harrison St, Suite \\ \#300, Chicago, IL 60612, USA. Email: kern.singh@rushortho.com.
}

\begin{abstract}
Intraoperative radiological imaging serves an essential role in many spine surgery procedures. It is critical that patients, staff and physicians have an adequate understanding of the risks and benefits associated with radiation exposure for all involved. In this review, we briefly introduce the current trends associated with intraoperative radiological imaging. With the increased utilization of minimally invasive spine surgery (MIS) techniques, the benefits of intraoperative imaging have become even more important. Less surgical exposure, however, often equates to an increased requirement for intraoperative imaging. Understanding the conventions for radiation measurement, radiological fundamental concepts, along with deterministic or stochastic effects gives a framework for conceptualizing how radiation exposure relates to the risk of various sequela. Additionally, we describe the various options surgeons have for intraoperative imaging modalities including those based on conventional fluoroscopy, computer tomography, and magnetic resonance imaging. We also describe different ways to prevent unnecessary radiation exposure including dose reduction, better education, and use of personal protective equipment (PPE). Finally, we conclude with a reflection on the progress that has been made to limit intraoperative radiation exposure and the promise of future technology and policy.
\end{abstract}

Keywords: Intraoperative imaging; ionizing radiation; DNA damage; genomic instability; shielding; distance; dose reduction; spine surgery

Submitted Jan 27, 2020. Accepted for publication Jun 11, 2020.

doi: $10.21037 /$ atm-20-1052

View this article at: http://dx.doi.org/10.21037/atm-20-1052

\section{Introduction}

The World Health Organization recognizes that excessive exposure to ionizing radiation increases the risk of harmful sequelae, such as cancer (1). Radiation exposure is particularly relevant among the surgical specialties that rely on various modalities of radiologic imaging and localization. Various examples of these technologies include fluoroscopy for imaging, intraoperative computed tomography (CT) for localization, radiopaque dye for visualization in vascular procedures, confirmation of alignment, or instrumentation placement in orthopaedic procedures (2). While general orthopaedic procedures frequently require imaging of the limbs or peripheral structures when placing implants, spine surgery routinely requires surgeons to place these devices in close proximity to structures of the central nervous system and neighboring vascular structures. In spine surgery, the most common procedure requiring use of ionizing radiation is the placement of posterior pedicle screws as erroneous screw placement can have catastrophic results.

Ensuring the proper positioning of surgical devices requires intraoperatively attained radiographic images. Increased exposure to various spectra of the electromagnetic spectrum 
is a necessary part of nearly all radiological imaging (3). Spine surgeons first made use of biplanar fluoroscopy which was used as an early radiological imaging modality. The radiation emitted during intraoperative fluoroscopic imaging places surgeons at risk for increased exposure to ionizing radiation and other resultant sequelae (4). As we will later discuss, some side effects include burns, cataracts, carcinogenesis, and hair loss (5). Over the past two decades, the utilization of intraoperative radiationemitting devices has risen with the increasing adoption of minimally-invasive surgical techniques (6-8). With less anatomic exposure, imaging is often required to verify the position of anatomy and instrumentation (9).

While MIS offers numerous purported advantages such as reduced hospital stays, decreased blood loss, a lower risk of infection and lower pain scores $(10,11)$, its practice requires frequent use of fluoroscopy for localization and placement of pedicle screws and interbody implants as the anatomic landmarks utilized in traditional, open spine surgery techniques are not directly visualized. Moreover, it has been observed that reducing fluoroscopy time and exposure are among the most difficult MIS skills to master (12). Despite these concerns, fluoroscopy remains the conventional intraoperative imaging modality used in MIS spine surgery despite its known risks (13-19).

Reducing radiation exposure to the patient, operating room staff, and surgeon may be accomplished through judicious use of intraoperative fluoroscopy, the use of emerging technologies and increasing emphasis on the use of personal protective equipment (PPE) (20). While opportunities to decrease radiation exposure while using traditional fluoroscopic methods are numerous, they are faced with significant barriers to implementation. Detailed mitigation and safety procedures can be cumbersome, are likely to be met with cultural resistance, and require significant healthcare workforce buy-in (21).

Many assert that new technologies are the likely solution for reducing intraoperative radiation exposure $(18,22,23)$. Proven technologies such as frameless image guidance and navigation systems have undergone changes to improve accuracy and streamline registration procedures. Other novel technologies are becoming increasingly utilized such as intraoperative computed tomography (CT) based guidance, IR-navigation that uses preoperative CT imaging, and three-dimensional (3D) fluoroscopy (24). Despite these advances, the strongest supporting evidence for these methods is based on small cohorts.

Finally, while institutions are required to provide education and appropriate PPE, there is a disconnect between compliance and recommendations (25). Even though required PPE items such as lead gowns, shields, gloves, or glasses, may be institutionally supplied, education regarding the use of such equipment, and lack of availability are among the most common reasons for a lack of adherence.

The objective of this review is to outline the physical and pathological origins of intraoperative radiation, to describe the various sources of intraoperative radiation exposure and the barriers that must be overcome to prevent radiation exposure, and finally to review future directions that may be most applicable to mitigating intraoperative radiation risks.

\section{Radiation emission and pathophysiological effects}

Conceptualizing the pathophysiology associated with ionizing radiation exposure requires a cursory understanding of how radiation exposure is measured, what types of exposure exist, as well as the associated short- and long-term physical effects. X-radiation (X-ray) is electromagnetic radiation that is commonly used in intraoperative imaging (fluoroscopy, CT). Radiation exposure was classically measured by the roentgen, which measures the intensity of $\mathrm{X}$-ray radiation to which one was exposed. More contemporary units of measurement include the average energy absorbed by unit mass (Gray or Rad) and effective dose (Sievert). The Gray (Gy) is defined as the absorption of one joule of radiation energy per kilogram of matter while the Rad is a unit of absorbed radiation dose (1 $\mathrm{rad}=0.01 \mathrm{~Gy}$ ). Alternatively, the Sivert is an effective dose, a measure of the overall detrimental health effects of ionizing radiation. It is calculated by weighting the concentration of energy imparted on each organ using factors that account for radiation-related mutagenic potential in reference populations and the radiation type. To better understand the difference between absorbed and effective dose, we can consider that a single radiograph from the posterioranterior chest delivers an absorbed dose to the posterior chest of 0.14 Gy $(9,26)$. When converted and weighted an effective dose, this is $0.03 \mathrm{mSv}$. A lumbar radiograph delivers approximately $1.5 \mathrm{mSv}$ and a lumbar CT roughly $15 \mathrm{mSv}$ to the patient (26).

There are three main sources of radiation in the operating room: direct radiation, scattered radiation, and leakage radiation (27). Direct radiation is emitted from the beam source toward the target to produce the radiograph. 
Scattered radiation is the phenomenon of deflected photons from the X-ray beam that have interacted with the patient. This phenomenon is known as Compton scattering and occurs when an X-ray interacts with matter and deflects instead of being absorbed. The majority of these scattered $\mathrm{X}$-rays are along the initial beam trajectory but they may also scatter in any direction. The magnitude of scattered radiation exposure depends on the strength of the X-ray source, the distance from the target being imaged, and the mass of the target. Leakage radiation is any radiation that escapes the X-ray tube housing which is not originating from the beam path. The magnitude of radiation from a source, be it direct, scattered or leaked, is inversely proportional to the square of the distance of the source to the surgeon or patient (27). For example, considering a point source of radiation that emits in all directions, it is understandable that, at greater distances away from the source the radiation is distributed over a larger and larger spherical surface.

The biological effects of ionizing radiation are classified into either deterministic or stochastic. Deterministic effects are the immediate changes to tissues such as skin erythema, hematopoietic damage, and fibrosis (27). Deterministic effects are the result of a large number of cells in an organ or tissue that are killed as the result of large radiation doses (28). Deterministic effects are only observed once a high threshold dose has been achieved. For example, during the 2011 Fukushima Daiichi nuclear disaster in Ōkuma, Fukushima Prefecture of Japan, workers were exposed to an unforeseen supply of radioactive water and this resulted in their hospitalization for the consequent radiation burns $(29,30)$. This threshold dose is much greater than those used in diagnostic imaging.

Ionizing radiation produces both direct and indirect damage to DNA including, base alteration, crosslinking, and strand breaks (31). The stochastic effect is cellular damage to DNA arising from low dose ionizing radiation exposure, such as those in the OR. The stochastic effect is the probability of experiencing an effect, which is directly proportional to the radiation dose (i.e., $10 \mathrm{~Gy}$ has a higher probability than $1 \mathrm{~Gy}$ ). For stochastic effects, the severity does not change with increases in dose. The only element that changes is the likelihood that damage will occur. Hence, there is no radiation dose threshold for cellular damage, as any amount of ionizing radiation imparts destructive energy on human cells that could ultimately result in malignant conditions.
Current standards on radiation safety are described by the US National Council on Radiation Protection \& Measurements (NCRP) and the International Commission on Radiological Protection (ICRP). ICRP recommends a dose limit for medical interventional procedures of a wholebody effective dose of $20 \mathrm{mSv} /$ year averaged over 5 years (28). Further guidance is specified that this is not to exceed $50 \mathrm{mSv}$ in any single year, an extremity dose of $500 \mathrm{mSv} / \mathrm{year}$, or a skin dose of $500 \mathrm{mSv} /$ year averaged over $1-\mathrm{cm}^{2}$ (28). Furthermore, no dose is advised at any time during pregnancy of $5 \mathrm{mSv}$, and no dose to the lens of the eye of $20 \mathrm{mSv} /$ year averaged over 5 years, not to exceed $50 \mathrm{mSv}$ in any single year (28). These recommended limits are meant to avoid deterministic effects and to ensure that stochastic effects are kept at an acceptable level (28). Notably, NRCP has a higher recommended occupational dose limit of $50 \mathrm{mSv} /$ year (32).

\section{Physician exposure}

Intraoperative surgeon exposure is predominantly encountered due to scatter radiation. Long term effects of exposure to ionizing radiation have been studied by tracking survivors of the Hiroshima atomic bomb (33). These studies based on this cohort have shown that $1 \mathrm{~Sv}$ of exposure imparts a $60 \%$ increase in developing solid malignancy (33).

Exposure effects can be systemic or local. Localized effects, for example, can include sequelae that develop after radiation exposure to the lens of the eye, resulting in the formation of cataracts. A consensus has not been reached on the threshold exposure that will result in cataract formation. This is in part due to the fact that cataracts may be caused by deterministic or stochastic effects (34). Ainsbury et al. evaluated data from atomic bomb survivors, clinical exposures, and occupational exposures, such as pilots and astronauts, and determined that the exposure threshold for posterior subcapsular cataracts was 0.5 Gy $(28,35)$. To put this in measurement in perspective, one study found that spine surgery patients were exposed to an average of 1,091 Gy with the use of conventional fluoroscopy (36).

In a survey of female orthopaedic, urology, and plastic surgeons $(n=1,203)$ who were exposed to fluoroscopy, Chou et al., reported that orthopaedic surgeons in this cohort had twice the expected rate of total cancers and 2.9 times the rate of expected breast cancers (37). Interestingly, the reported rate of cancer from urology and plastic surgeons was not statistically different from their expected rate. 


\section{Intraoperative imaging modalities: spine surgery sources of radiation}

Spinal imaging and navigation systems play an irreplaceable role in accurate instrumentation placement. There are various options available for intraoperative imaging, each with its own set of unique advantages and disadvantages. Traditional fluoroscopy is typically the easiest to adopt and has the fewest barriers to implementation, while other techniques-e.g., navigation, robotics-which promise equivalent or increased accuracy with decreased radiation exposure may be cost-prohibitive, involve a change in workflow or specialized training requiring adoption by OR staff, and often come with a new set of potential pitfalls and a corresponding learning curve for the surgeon.

\section{Intraoperative navigation}

Spinal navigation systems typically function through the synchrony of multiple peripheral units. For example, radiographic imaging data is often collected of the relevant anatomy, uploaded into a computer which, in turn, constructs a $3 \mathrm{D}$ image. The computer also integrates several other components such as optical cameras, specialized surgical instrumentation, and tools which can all be tracked relative to surgical field reference points $(38,39)$. The computer can then guide instrumentation insertion without the need for continuously gathering fluoroscopic imagery (40).

Early navigation systems primarily use preoperative imaging, which entails a registration process (39). The registration process ensures that references on the preoperative CT or MRI are matched with physical points in the surgical field. This process is often cumbersome and time-intensive. Likewise, operative positioning of the patient can move anatomic relationships that are not reflected in preoperative imaging (41-44). Hence, navigation systems that make use of $3 \mathrm{D}$ intraoperative images have been developed and these can provide automated registration throughout the operation. These systems not only save time, but also avoid navigation errors that can arise with preoperative image guidance systems, such as inaccurate point or surface matching (45).

The resulting images can be utilized for either active or passive navigation. Active navigation systems can prevent movement beyond boundaries, or they can even perform certain tasks. Passive navigation systems provide location and imaging information without limiting movement. Given the variety of options and uses for pre- and postoperative imaging modalities, designing and using these systems in a way that optimizes image quality and reduces radiation exposure is more of a concern than ever before. Modalities utilized include CT or MRI. Due to their prevalence, ease of use and familiarity, there has been substantially more research investigating CT-based systems (46). CT based systems have demonstrated notable reductions in the frequency of misplaced spine surgery instrumentation.

\section{Isocentric C-arms}

$\mathrm{C}$-arms can be contrasted against legacy two-dimensional fluoroscopy primarily because the $\mathrm{C}$-arm allows an $\mathrm{X}$-ray tube to rotate over a $190^{\circ}$ arc about an isocentric point of interest. This rotation along with a wide aperture allows for the acquisition of 100 two-dimensional images, that are attained at equidistant angles. After acquiring, the images are reconstructed into a 3D image with volumes in excess of $15-\mathrm{cm}$ (47-49). While several studies have observed that intraoperative isocentric devices that are comparable to CT insofar as diagnostic capability $(42,50)$, others have noted that $\mathrm{C}$-arms may be limited in the cervical-thoracic region (51). C-arm devices can also function as standard fluoroscopic imaging systems and they can be used for registering patient anatomic landmarks with navigation systems (49).

As with any imaging modality, radiation exposure is an important consideration in patient care. However, intraoperative radiation exposure also means that the hospital staff will be at risk for exposure during each surgery. The Iso- $\mathrm{C}^{3 \mathrm{D}}$ is promising in this regard because it has been determined to produce images with comparable quality to postoperative CT scans, albeit with a reduced radiation signature. Thus, the Iso- $\mathrm{C}^{3 \mathrm{D}}$ can be used to replace postoperative $\mathrm{CT}$ and reduce radiation exposure for the patient.

To lessen ionizing radiation exposure and fluoroscopy time, researchers have utilized Iso- $\mathrm{C}^{3 \mathrm{D}}$ arms instead of standard fluoroscopy $(42,52,53)$. One study compared the two methods of measurement amongst 18 minimally invasive transforaminal lumbar interbody fusion procedures (MIS TLIF) on cadavers (52). Overall, fluoroscopy time was lower despite a longer setup in the Iso- $\mathrm{C}^{3 \mathrm{D}}$ group. Radiation exposure, which was measured in millirems (mREM), was not discernible in the Iso- $\mathrm{C}^{3 \mathrm{D}}$ group, whereas it was 12.4 mREM in the standard group (52). A similar study involved 4 cadaveric lumbar pedicle screw placements while comparing Iso- $\mathrm{C}^{3 \mathrm{D}}$ and standard fluoroscopy (53). This study also demonstrated less radiation exposure in the Iso- 
$\mathrm{C}^{3 \mathrm{D}}$ group. The use of Iso- $\mathrm{C}^{3 \mathrm{D}}$ is not only advantageous due to reduced radiation, it has also demonstrated increased accuracy when placing pedicle screws.

One disadvantage of the Iso- $\mathrm{C}^{3 \mathrm{D}}$ is that its $190^{\circ}$ rotation limits the device to image three to five vertebral levels at a time (46). Spine surgeries that require scanning of more levels may require more than one sequential scan. Beyond interrupting the task flow of the surgery and increasing operative duration, it also increases the amount of radiation exposure (50).

\section{O-Arms}

In comparison to $\mathrm{C}$-arms, $\mathrm{O}$-arms have a full $360^{\circ}$ image acquisition capability due to their circular gantry. O-arms have an anatomical registration system that is similar to C-arms.

They are also typically capable of acquiring more images over a shorter period of time than are $\mathrm{C}$-arms. In their standard 3D volumetric imaging mode, $\mathrm{O}$-arms will acquire roughly 400 images over $360^{\circ}$ in 14 seconds (45). The time and number of images is roughly doubled in high definition modes. O-arms were the first to offer a standard or high definition mode.

Despite these advantages, there is disagreement on the utility of $\mathrm{O}$-arm imaging in terms of reducing radiation. The findings of multiple studies demonstrate that despite decreased radiation exposure to the surgeon and clinical staff, who have the advantage of being able to leave the room or cover behind a mobile shield, there is overall increased radiation towards the patient (18,54-58). Comparisons between $\mathrm{C}$-arm and $\mathrm{O}$-arm imaging have replicated these results in cadaveric studies, most notably in the analysis of 160 pedicle screw placements (58). It was found that clinicians and operating room staff were not exposed to any radiation in $\mathrm{O}$-arm imaging, whereas $60.75 \mathrm{mREM}$ of radiation exposure was attributed to $\mathrm{C}$-arm imaging. Conversely, the cadavers were exposed to much higher radiation in the $\mathrm{O}$-arm group as compared to the C-arm group (58). An additional study found similar results when comparing $\mathrm{O}$-arm and $\mathrm{C}$-arm fluoroscopy amongst posterior pedicle screw insertions (18). In a cohort of 73 patients, those whose procedure involved $\mathrm{O}$-arm imaging had a radiation exposure that was 8.74 times that of the operating room clinicians and staff. Overall, these patients also had a higher mean effective dose radiation of $1.09 \mathrm{mSv}$ when compared to patients who underwent the same procedure with C-arm fluoroscopy after MIS or open procedures. These findings demonstrate that clinicians must consider the radiation risks to the patient when choosing $\mathrm{O}$-arm imaging, despite the benefit to the clinicians.

\section{Intraoperative MRI}

Intraoperative MRI enhances the ability to visualize soft tissue in the spine, which is why it is often used in tumor removal (59). Although intraoperative MRI is an established and well-researched technique in neurological surgery and tumor removal, it has not been researched as heavily in degenerative spine surgery. Researchers have studied intraoperative MRI in transforaminal endoscopic lumbar discectomy for patients with disk herniation and have found that MRI can aid in locating surgical entry point and instrumental trajectory as it relates to the intervertebral disk space (60). It has also been noted that intraoperative MRI can help to identify neural and vascular tissue, as well as insufficient decompression, which overall reduces surgical complications (60). To our knowledge, there are no studies evaluating intraoperative MRI with MIS, although one interventional neurology study found that intraoperative MRI is approximately double the cost of intraoperative CT (61).

\section{Procedure-related exposure}

\section{Differences in radiation exposure by procedure: MIS vs. open}

Despite minimizing exposure of the patient during surgery, as previously mentioned, MIS is even more dependent than open surgery is on intraoperative imaging (62). MIS presents many potential advantages, such as less patientreported pain durations and severity levels, less tissue trauma, less bleeding, and smaller wounds. Faster recovery times have been attributed to these and other aspects. However, due to the nature of MIS and its overall approach to lessen adjacent tissue damage, there is minimal spine exposure which results in less visibility. For this reason, radiological imaging plays a significant role in MIS.

Radiation exposure is an unfortunate, yet essential aspect of the most common tools used to visualize surgical instrumentation. Due to the necessary verification of instrumentation with radiologic imaging in MIS, ionizing radiation is an unavoidable necessity for both surgeons and patients. The presence of this workplace hazard makes it desirable to monitor intraoperative exposure. Hence, exposure and variations in exposure are often 
measured throughout procedures through fluoroscopic monitoring. This is most applicable during the placement of percutaneous screws in MIS (3). With the concern and actual effects of radiation exposure that have now been realized, several investigators have attempted to measure the intraoperative radiation exposure for both surgeons and patients during various spine procedures (3,63-66). Indeed, one Italian institution described their orthopaedic surgeons to have increased their risk of cancer by five times (13).

\section{Fusion procedures}

A recent meta-analysis determined that, compared to open spine fusion surgeries, MIS TLIF can expose patients to as much as 2.4 times more radiation (67). One study measured radiation exposure to both surgeons and patients undergoing minimally invasive spine fusions and observed total radiation exposure for patients was $3.47 \pm 2.12 \mathrm{Rad}$ which broke down to $0.46 \mathrm{Rad} / \mathrm{screw}$. The mean radiation to the surgeon was estimated to be $8.61 \mu \mathrm{Sv}$, which was divided up to $1.06 \mu \mathrm{Sv} / \mathrm{screw}$. When compared to TLIF or $\mathrm{A} / \mathrm{P}$ fusion procedures, XLIF procedures exposed the surgeon and patient to nearly twice as much ionizing radiation, Farber et al. did note that when compared to using fluoroscopy in the general setting, low-dose pulse setting for fluoroscopy could significantly reduce the level of exposure $(1.40 \pm 0.65$ vs. $0.79 \pm 0.65 \mu \mathrm{S} v /$ screw, $\mathrm{P}=0.0002)$. One technique, although part of a cadaveric study, used preoperative $\mathrm{C}$-arm fluoroscopy to demonstrate reduced intraoperative radiation to below detectable levels (52).

\section{Other spine procedures}

Other investigators have measured radiation exposure for vertebroplasty, kyphoplasty, pedicle screw insertion, microdiscectomy, and endoscopic procedures (10,14,68-73). In general, MIS techniques appear to impose more of a radiation exposure risk than do open techniques. Radiation exposure has been compared between open versus MIS microdiscectomies (74). Compared to the open technique, MIS microdiscectomies were again observed to have a statistically significant increase in radiation exposure for the surgeon, including areas such as the chest, eyes, hand, and thyroid. Others have investigated endoscopic procedures. In one investigation with percutaneous endoscopic lumbar discectomies, the authors observed similar surgeon radiation exposure levels $(0.1718 \mu \mathrm{Sv} /$ level $)$ to those reported in common MIS procedures (66).

\section{Prevention}

\section{Barriers to exposure safety}

Current barriers facing trainees and practicing physicians are multifaceted, ranging from education, protective equipment, and local/institutional safety policies. While the previously mentioned safety policies are put forth by national (NRCP) and international (IRCP) radiation safety organizations, these recommendations have a varied application at the trainee and physician levels throughout orthopaedic surgery $(28,32,75)$.

In one cohort of 26 orthopaedic trainees, just over $50 \%$ of the trainees felt they received adequate radiation safety training (76). Overall, the cohort reported high compliance with lead apron use (96\%), while in contrast, their dosimeters were rarely used (27\%) (76). The two greatest barriers to using protective equipment were perceived impracticality and lack of availability (76). In another survey of 50 general surgery trainees from the United Kingdom, only $16 \%$ reported they had read literature regarding radiation safety, $22 \%$ utilized a thyroid shield, and a slim $6 \%$ were aware of the principle "As Low As Reasonably Achievable (ALARA)" (77).

The American Academy of Orthopaedic Surgeons (AAOS) recommends a three-pronged approach to reducing radiation exposure to surgeons, patients, and associated staff which include: educating users on safe techniques to reduce exposure, utilization of protective equipment and dosemeasuring methods, as well as the regular maintenance of imaging equipment and shielding. Institutional policies vary widely and, unfortunately, there are no current standardized educational curriculums on radiation safety for orthopaedic residency training $(78)$.

\section{PPE}

Standard radiation protection, such as lead aprons, skirts, thyroid, and eye shields, should be worn during all procedures and may be supplemented with more specialized equipment to further mitigate radiation exposure (16). A mobile shielding device has been observed to reduce the exposure dose to a surgeon by $75-86.1 \%$ in vertebroplasties $(14,79)$. Wearing lead gloves while performing percutaneous vertebroplasty procedures has also been reported to reduce radiation exposure by $75 \%$, reducing the treatment associated dose to the hand from 1.81 to $0.49 \mathrm{mSv}$ (71). Although this may seem like a minuscule improvement, for a surgeon who performs hundreds of 
procedures a year, this can safely increase the number of procedures performed without increasing exposure to the hand when compared to performing procedures without lead gloves. All imaging modalities benefit from further protection. While using a cone-beam CT for 3D image guidance, having the surgeon stand behind a lead shield 10 feet away has been observed to reduce scatter radiation to the torso from $5 \mathrm{rem}$ to $3.6 \mathrm{rem} / \mathrm{spin}$ (55). Ahn et al. demonstrated that without the use of protective radiation shielding, a surgeon would be limited to 291 percutaneous endoscopic lumbar discectomies annually (i.e., prior to exceeding the maximum annual dose limit) (66). In this same study, the addition of a lead collar and apron, the radiation dose was reduced by $96.9 \%$ and $94.2 \%$, respectively (66). Another study that evaluated the radiation dose from $\mathrm{C}$-arm fluoroscopy during a simulated spine procedure, recommended the best steps to take to reduce exposure were to: increase the distance from the source, wear all protective equipment (apron, thyroid shield, and goggles), avoid direct exposure to the hands, and avert one's head if no eye protection is available (16).

\section{Fluoroscopic dose reduction}

The principals inherent to ALARA are essential to safe radiation exposure practices. The foundational tenets include decreasing the dose, increasing the distance to the source, decreasing the time exposed, or a combination of all three. There is a plethora of research that has evaluated and demonstrated the success of this principle in reducing radiation exposure. Acquisition of fluoroscopic images may be modified to reduce exposure to the patient and surgeon. Switching from a continuous fluoroscopic mode to a pulsed mode has been shown to reduce radiation dose $(80,81)$. Physicians must attempt to balance useful image quality while adhering to the ALARA principle. In one cohort of 50 patients undergoing MIS TLIF, Clark et al. successfully implemented a low dose pulsed fluoroscopy protocol that decreased fluoroscopy time and radiation dose without compromising image quality (82). Another study reported that in 158 patients undergoing spinal interventions a $56.7 \%$ reduction in radiation exposure was achieved through the use of pulsed low dose fluoroscopy (81). Using pulsed and low dose settings does pose a risk for producing lower image quality (81), although some radiological studies have demonstrated no perceivable difference $(83,84)$.

One development that has allowed for the focusing of radiation, beam collimation, allows the operator to concentrate the radiation on a point of interest while avoiding inadvertent targets. This is achieved by the application of lead shutters that restrict the X-ray beam to only the anatomy of interest. Obvious advantages are reducing radiation doses to the patient and surgeon. Using cadavers and Monte Carlo risk and outcome simulation, Yamashita et al. demonstrated that the collimation of C-arm fluoroscopy reduced $65 \%$ of the radiation exposure to the surgeon's hand and thyroid (85). Artner et al. used low dose CT-guided injections to demonstrate that low dose settings can also be applied to CT-guided procedures (38). An $85 \%$ dose reduction was observed when using a low dose mode while maintaining the safety and precision of epidural and periradicular injections (38). In addition to changes in mode settings, modifications in how the surgeon manually manipulates the acquisition of images may reduce radiation exposure. Freezing the last image on the monitor, known as "image hold", allows the surgeon to plan the next maneuver while avoiding additional inadvertent radiation to the patient and OR staff (86). Intermittent fluoroscopy is the method of only activating the X-ray beam for a few seconds at a time to visualize structures (86). Taken together, even in radiologically intensive operative techniques, surgeons have many options available that can assist in the delicate balance between image quality and radiation exposure safety.

\section{Conclusions}

The critical balance to optimize care while limiting radiation exposure for patients, hospital staff, and community members is a challenge that continues to evolve. Prototypes such as hybrid operating rooms are soon expected to be equipped with automated C-arms with 3D cone-beam CTs. These are hypothesized to offer the automation of significant portions of image collection processes and to potentially eliminate the exposure burden currently imposed on hospital staff (69). Robotic surgery also may offer new methods to limit radiation exposure for hospital staff. While there is much promise with these systems, it is also important to be cognizant of potential limitations such as cost, maintenance requirements, and operative time durations. Until such time that technological progress changes the current paradigm of intraoperative radiation, the fundamentals of decreasing exposure-distance, dose reduction, and shieldingremain essential pillars for practitioners who utilize ionizing radiation as an integral part of their surgical practice. 


\section{Acknowledgments}

Funding: None.

\section{Footnote}

Provenance and Peer Review: This article was commissioned by the Guest Editor (Dr. Sheeraz Qureshi) for the series "Current State of Intraoperative Imaging" published in Annals of Translational Medicine. The article was sent for external peer review organized by the Guest Editor and the editorial office.

Conflicts of Interest: All authors have completed the ICMJE uniform disclosure form (available at http://dx.doi. org/10.21037/atm-20-1052). The series "Current State of Intraoperative Imaging" was commissioned by the editorial office without any funding or sponsorship. KS reports personal fees and other from Zimmer Biomet, other from Stryker, other from RTI Surgical, other from Lippincott Williams and Wilkins, other from Avaz Surgical LLC, other from Vital 5 LLC, personal fees from K2M, nonfinancial support and other from TDi LLC, non-financial support from Minimally Invasive Spine Study Group, nonfinancial support from Contemporary Spine Surgery, nonfinancial support from Orthopedics Today, non-financial support from Vertebral Columns, grants from Cervical Spine Research Society, outside the submitted work. The authors have no other conflicts of interest to declare.

Ethical Statement: The authors are accountable for all aspects of the work in ensuring that questions related to the accuracy or integrity of any part of the work are appropriately investigated and resolved.

Open Access Statement: This is an Open Access article distributed in accordance with the Creative Commons Attribution-NonCommercial-NoDerivs 4.0 International License (CC BY-NC-ND 4.0), which permits the noncommercial replication and distribution of the article with the strict proviso that no changes or edits are made and the original work is properly cited (including links to both the formal publication through the relevant DOI and the license). See: https://creativecommons.org/licenses/by-nc-nd/4.0/.

\section{References}

1. Ionizing radiation, health effects and protective measures.
Available online: https://www.who.int/news-room/factsheets/detail/ionizing-radiation-health-effects-andprotective-measures

2. Hecht AC, Koehler SM, Laudone JC, et al. Is intraoperative CT of posterior cervical spine instrumentation cost-effective and does it reduce complications? Clin Orthop Relat Res 2011;469:1035-41.

3. Harrison Farber S, Nayar G, Desai R, et al. Radiation exposure to the surgeon during minimally invasive spine procedures is directly estimated by patient dose. Eur Spine J 2018;27:1911-7.

4. Srinivasan D, Than KD, Wang AC, et al. Radiation safety and spine surgery: systematic review of exposure limits and methods to minimize radiation exposure. World Neurosurg 2014;82:1337-43.

5. Blakely EA. Biological effects of cosmic radiation: deterministic and stochastic. Health Phys 2000;79:495-506.

6. Singer G. Occupational radiation exposure to the surgeon. J Am Acad Orthop Surg 2005;13:69-76.

7. Brenner DJ, Hall EJ. Computed Tomography - An Increasing Source of Radiation Exposure. N Engl J Med 2007;357:2277-84.

8. Fazel R, Krumholz HM, Wang Y, et al. Exposure to lowdose ionizing radiation from medical imaging procedures. N Engl J Med 2009;361:849-57.

9. Yu E, Khan SN. Does less invasive spine surgery result in increased radiation exposure? A systematic review. Clin Orthop Relat Res 2014;472:1738-48.

10. Mroz TE, Yamashita T, Davros WJ, et al. Radiation Exposure to the Surgeon and the Patient During Kyphoplasty. J Spinal Disord Tech 2008;21:96-100.

11. Terman SW, Yee TJ, Lau D, et al. Minimally invasive versus open transforaminal lumbar interbody fusion: comparison of clinical outcomes among obese patients. J Neurosurg Spine 2014;20:644-52.

12. Kumar A, Merrill RK, Overley SC, et al. Radiation Exposure in Minimally Invasive Transforaminal Lumbar Interbody Fusion: The Effect of the Learning Curve. Int J Spine Surg 2019;13:39-45.

13. Mastrangelo G, Fedeli U, Fadda E, et al. Increased cancer risk among surgeons in an orthopaedic hospital. Occup Med (Lond) 2005;5 5:498-500.

14. Fitousi NT, Efstathopoulos EP, Delis HB, et al. Patient and staff dosimetry in vertebroplasty. Spine 2006;31:E8849; discussion E890.

15. Dewey P, Incoll I. Evaluation of thyroid shields for reduction of radiation exposure to orthopaedic surgeons. 
Aust N Z J Surg 1998;68:635-6.

16. Lee K, Lee KM, Park MS, et al. Measurements of surgeons' exposure to ionizing radiation dose during intraoperative use of C-arm fluoroscopy. Spine 2012;37:1240-4.

17. Giordano BD, Baumhauer JF, Morgan TL, et al. Cervical spine imaging using mini--C-arm fluoroscopy: patient and surgeon exposure to direct and scatter radiation. J Spinal Disord Tech 2009;22:399-403.

18. Mendelsohn D, Strelzow J, Dea N, et al. Patient and surgeon radiation exposure during spinal instrumentation using intraoperative computed tomography-based navigation. Spine J 2016;16:343-54.

19. Perisinakis K, Theocharopoulos N, Damilakis J, et al. Estimation of patient dose and associated radiogenic risks from fluoroscopically guided pedicle screw insertion. Spine 2004;29:1555-60.

20. Vaishnav AS, Merrill RK, Sandhu H, et al. A Review of Techniques, Time Demand, Radiation Exposure, and Outcomes of Skin-anchored Intraoperative 3D Navigation in Minimally Invasive Lumbar Spinal Surgery. Spine 2020;45:E465-76.

21. Lukoff J, Olmos J. Minimizing Medical Radiation Exposure by Incorporating a New Radiation 'Vital Sign' into the Electronic Medical Record: Quality of Care and Patient Safety. Perm J 2017;21:17-007.

22. Noriega DC, Hernández-Ramajo R, Rodríguez-Monsalve Milano F, et al. Risk-benefit analysis of navigation techniques for vertebral transpedicular instrumentation: a prospective study. Spine J 2017;17:70-5.

23. Tajsic T, Patel K, Farmer R, et al. Spinal navigation for minimally invasive thoracic and lumbosacral spine fixation: implications for radiation exposure, operative time, and accuracy of pedicle screw placement. Eur Spine J 2018;27:1918-24.

24. Pennington Z, Cottrill E, Westbroek EM, et al. Evaluation of surgeon and patient radiation exposure by imaging technology in patients undergoing thoracolumbar fusion: systematic review of the literature. Spine J 2019;19:1397-411.

25. Bowman JR, Razi A, Watson SL, et al. What Leads to Lead: Results of a Nationwide Survey Exploring Attitudes and Practices of Orthopaedic Surgery Residents Regarding Radiation Safety. J Bone Joint Surg Am 2018;100:e16.

26. Giordano BD, Grauer JN, Miller CP, et al. Radiation exposure issues in orthopaedics. J Bone Joint Surg Am 2011;93:e69.

27. Mahesh M. The Essential Physics of Medical Imaging.
Third Edition. Philadelphia: Lippincott Williams \& Wilkins, 2012:1048.

28. López PO, Dauer LT, Loose R, et al. ICRP Publication 139: Occupational Radiological Protection in Interventional Procedures. Ann ICRP 2018;47:1-118.

29. Authority NR. International Atomic Energy Agency (IAEA) international fact finding expert mission of the nuclear accident following the great east japan earthquake and tsunami (24 May-1 June 2011). Available online: https://dspace.jaea.go.jp/handle/faa/77156/

30. McLaughlin PD, Jones B, Maher MM. An update on radioactive release and exposures after the Fukushima Daiichi nuclear disaster. Br J Radiol 2012;85:1222-5.

31. Morgan WF, Day JP, Kaplan MI, et al. Genomic Instability Induced by Ionizing Radiation. Radiat Res 1996;146:247.

32. National Council on Radiation Protection and Measurements. Limitation of Exposure to Ionizing Radiation: Recommendations of the National Council on Radiation Protection and Measurements. NCRP. Available online: https://play.google.com/store/books/ details?id=uFzLJu-9x8wC

33. Pierce DA, Preston DL. Radiation-related cancer risks at low doses among atomic bomb survivors. Radiat Res 2000;154:178-86.

34. Hayda RA, Hsu RY, DePasse JM, et al. Radiation Exposure and Health Risks for Orthopaedic Surgeons. J Am Acad Orthop Surg 2018;26:268-77.

35. Ainsbury EA, Bouffler SD, Dörr W, et al. Radiation cataractogenesis: a review of recent studies. Radiat Res 2009;172:1-9.

36. Gebhard FT, Kraus MD, Schneider E, et al. Does computer-assisted spine surgery reduce intraoperative radiation doses? Spine 2006;31:2024-7; discussion 2028.

37. Chou LB, Lerner LB, Harris AHS, et al. Cancer Prevalence among a Cross-sectional Survey of Female Orthopedic, Urology, and Plastic Surgeons in the United States. Womens Health Issues 2015;25:476-81.

38. Artner J, Lattig F, Reichel H, et al. Effective radiation dose reduction in computed tomography-guided spinal injections: a prospective, comparative study with technical considerations. Orthop Rev (Pavia) 2012;4:e24.

39. Rahmathulla G, Nottmeier EW, Pirris SM, et al. Intraoperative image-guided spinal navigation: technical pitfalls and their avoidance. Neurosurg Focus 2014;36:E3.

40. Holly LT. Image-guided spinal surgery. Int J Med Robot 2006;2:7-15.

41. Bledsoe JM, Fenton D, Fogelson JL, et al. Accuracy of upper thoracic pedicle screw placement using three- 
dimensional image guidance. Spine J 2009;9:817-21.

42. Hott JS, Papadopoulos SM, Theodore N, et al. Intraoperative Iso- $\mathrm{C} \mathrm{C}$-arm navigation in cervical spinal surgery: review of the first 52 cases. Spine 2004;29:2856-60.

43. Holly LT, Foley KT. Three-dimensional fluoroscopyguided percutaneous thoracolumbar pedicle screw placement: Technical note. J Neurosurg 2003;99:324-9.

44. Nakashima H, Sato K, Ando T, et al. Comparison of the percutaneous screw placement precision of isocentric C-arm 3-dimensional fluoroscopy-navigated pedicle screw implantation and conventional fluoroscopy method with minimally invasive surgery. J Spinal Disord Tech 2009;22:468-72.

45. Medtronic. O-arm - Surgical Imaging Systems. Available online: https://www.medtronic.com/us-en/healthcareprofessionals/products/neurological/surgical-imagingsystems/o-arm.html

46. Qureshi S, Lu Y, McAnany S, et al. Three-dimensional Intraoperative Imaging Modalities in Orthopaedic Surgery: A Narrative Review. J Am Acad Orthop Surg 2014;22:800-9.

47. Neo M, Sakamoto T, Fujibayashi S, et al. The clinical risk of vertebral artery injury from cervical pedicle screws inserted in degenerative vertebrae. Spine 2005;30:2800-5.

48. Wiesel SW. Operative Techniques in Orthopaedic Surgery. Lippincott Williams \& Wilkins. Available online: https:// play.google.com/store/books/details?id=tB58pMV4xCwC

49. Cios Spin. Available online: https://www.siemenshealthineers.com/en-us/surgical-c-arms-and-navigation/ mobile-c-arms/cios-spin

50. Kim JM, Bowers AL, Chin KR. Intraoperative Imaging Techniques in Spine Surgery. Semin Spine Surg 2007;19:78-86.

51. Hecht N, Yassin H, Czabanka M, et al. Intraoperative Computed Tomography Versus 3D C-Arm Imaging for Navigated Spinal Instrumentation. Spine 2018;43:370-7.

52. Kim CW, Lee YP, Taylor W, et al. Use of navigationassisted fluoroscopy to decrease radiation exposure during minimally invasive spine surgery. Spine J 2008;8:584-90.

53. Smith HE, Welsch MD, Sasso RC, et al. Comparison of radiation exposure in lumbar pedicle screw placement with fluoroscopy vs computer-assisted image guidance with intraoperative three-dimensional imaging. J Spinal Cord Med 2008;31:532-7.

54. Bandela JR, Jacob RP, Arreola M, et al. Use of CT-based intraoperative spinal navigation: management of radiation exposure to operator, staff, and patients. World Neurosurg
2013;79:390-4.

55. Nottmeier EW, Pirris SM, Edwards S, et al. Operating room radiation exposure in cone beam computed tomography-based, image-guided spinal surgery: clinical article. J Neurosurg Spine 2013;19:226-31.

56. Lange J, Karellas A, Street J, et al. Estimating the effective radiation dose imparted to patients by intraoperative conebeam computed tomography in thoracolumbar spinal surgery. Spine 2013;38:E306-12.

57. Pitteloud N, Gamulin A, Barea C, et al. Radiation exposure using the $\mathrm{O}$-arm ${ }^{\circledR}$ surgical imaging system. Eur Spine J 2017;26:651-7.

58. Tabaraee E, Gibson AG, Karahalios DG, et al. Intraoperative cone beam-computed tomography with navigation $(\mathrm{O}-\mathrm{ARM})$ versus conventional fluoroscopy (C-ARM): a cadaveric study comparing accuracy, efficiency, and safety for spinal instrumentation. Spine 2013;38:1953-8.

59. Jolesz FA. Future perspectives for intraoperative MRI. Neurosurg Clin N Am 2005;16:201-13.

60. Choi G, Modi HN, Prada N, et al. Clinical results of XMR-assisted percutaneous transforaminal endoscopic lumbar discectomy. J Orthop Surg Res 2013;8:14.

61. Maurer MH, Schreiter N, de Bucourt M, et al. Cost comparison of nerve root infiltration of the lumbar spine under MRI and CT guidance. Eur Radiol 2013;23:1487-94.

62. Covarrubias J, Say I, Bhatia N, et al. How to Reduce Radiation Exposure During Spine Surgery. Contemporary Spine Surgery 2017;18:1.

63. Bindal RK, Glaze S, Ognoskie M, et al. Surgeon and patient radiation exposure in minimally invasive transforaminal lumbar interbody fusion. J Neurosurg Spine 2008;9:570-3.

64. Ul Haque M, Shufflebarger HL, O'Brien M, et al. Radiation exposure during pedicle screw placement in adolescent idiopathic scoliosis: is fluoroscopy safe? Spine 2006;31:2516-20.

65. Taher F, Hughes AP, Sama AA, et al. 2013 Young Investigator Award winner: how safe is lateral lumbar interbody fusion for the surgeon? A prospective in vivo radiation exposure study. Spine 2013;38:1386-92.

66. Ahn Y, Kim CH, Lee JH, et al. Radiation exposure to the surgeon during percutaneous endoscopic lumbar discectomy: a prospective study. Spine 2013;38:617-25.

67. Kim CH, Lee CH, Kim KP. How High Are Radiationrelated Risks in Minimally Invasive Transforaminal Lumbar Interbody Fusion Compared With Traditional 
Open Surgery? Clin Spine Surg 2016;29:52-9.

68. Kallmes DF, O E, Roy SS, et al. Radiation dose to the operator during vertebroplasty: prospective comparison of the use of 1-cc syringes versus an injection device. AJNR Am J Neuroradiol 2003;24:1257-60.

69. Faciszewski T, Kruger R. 60. Radiation dose reduction to medical staff during vertebroplasty: a review of techniques and methods to mitigate occupational dose. Spine J 2003;3:96.

70. Harstall R, Heini PF, Mini RL, et al. Radiation exposure to the surgeon during fluoroscopically assisted percutaneous vertebroplasty: a prospective study. Spine 2005;30:1893-8.

71. Synowitz M, Kiwit J. Surgeon's radiation exposure during percutaneous vertebroplasty. J Neurosurg Spine 2006;4:106-9.

72. Jones DP, Robertson PA, Lunt B, et al. Radiation exposure during fluoroscopically assisted pedicle screw insertion in the lumbar spine. Spine 2000;25:1538-41.

73. Rampersaud YR, Foley KT, Shen AC, et al. Radiation exposure to the spine surgeon during fluoroscopically assisted pedicle screw insertion. Spine 2000;25:2637-45.

74. Mariscalco MW, Yamashita T, Steinmetz MP, et al. Radiation exposure to the surgeon during open lumbar microdiscectomy and minimally invasive microdiscectomy: a prospective, controlled trial. Spine 2011;36:255-60.

75. The 2007 Recommendations of the International Commission on Radiological Protection. ICRP publication 103. Ann ICRP 2007;37:1-332.

76. Nugent M, Carmody O, Dudeney S. Radiation safety knowledge and practices among Irish orthopaedic trainees. Ir J Med Sci 2015;184:369-73.

77. Khan F, Ul-Abadin Z, Rauf S, et al. Awareness and attitudes amongst basic surgical trainees regarding

Cite this article as: Jenkins NW, Parrish JM, Sheha ED, Singh K. Intraoperative risks of radiation exposure for the surgeon and patient. Ann Transl Med 2021;9(1):84. doi: 10.21037/atm-20-1052 radiation in orthopaedic trauma surgery. Biomed Imaging Interv J 2010;6:e25.

78. Kaplan DJ, Patel JN, Liporace FA, et al. Intraoperative radiation safety in orthopaedics: a review of the ALARA (As low as reasonably achievable) principle. Patient Saf Surg 2016;10:27.

79. Kruger R, Faciszewski T. Radiation dose reduction to medical staff during vertebroplasty: a review of techniques and methods to mitigate occupational dose. Spine 2003;28:1608-13.

80. Vetter S, Faulkner K, Strecker EP, et al. Dose Reduction and Image Quality in Pulsed Fluoroscopy. Radiat Prot Dosimetry 1998;80:299-301.

81. Goodman BS, Carnel CT, Mallempati S, et al. Reduction in average fluoroscopic exposure times for interventional spinal procedures through the use of pulsed and low-dose image settings. Am J Phys Med Rehabil 2011;90:908-12.

82. Clark JC, Jasmer G, Marciano FF, et al. Minimally invasive transforaminal lumbar interbody fusions and fluoroscopy: a low-dose protocol to minimize ionizing radiation. Neurosurg Focus 2013;35:E8.

83. Hernandez RJ, Goodsitt MM. Reduction of radiation dose in pediatric patients using pulsed fluoroscopy. AJR Am J Roentgenol 1996;167:1247-53.

84. Boland GW, Murphy B, Arellano R, et al. Dose reduction in gastrointestinal and genitourinary fluoroscopy: use of grid-controlled pulsed fluoroscopy. AJR Am J Roentgenol 2000;175:1453-7.

85. Yamashita K, Higashino K, Hayashi H, et al. Pulsation and Collimation During Fluoroscopy to Decrease Radiation: A Cadaver Study. JB JS Open Access 2017;2:e0039.

86. Mahesh M. Fluoroscopy: patient radiation exposure issues. Radiographics 2001;21:1033-45. 